\title{
Comprehensive Characterization of Commercially Available Canine Training Aids
}

Christopher A. Tipple ${ }^{1}$, Patricia T. Caldwell ${ }^{2}$, Brian M. Kile ${ }^{2}$, Douglas J. Beussman ${ }^{2}$, Blake Rushing $^{2}$, Natalie J. Mitchell ${ }^{2}$, Christian J. Whitchurch ${ }^{2}$, Martin Grime ${ }^{3}$, Rex Stockham ${ }^{4}$, and Brian A. Eckenrode ${ }^{1^{*}}$

${ }^{1}$ Counterterrorism and Forensic Science Research Unit, Federal Bureau of Investigation Laboratory Division, Quantico, VA 22135

${ }^{2}$ Counterterrorism and Forensic Science Research Unit, Visiting Scientist Program, Federal Bureau of Investigation Laboratory Division, Quantico, VA 22135

${ }^{3}$ GSS International Ltd, Romsey, Hampshire, SO51 5SW, United Kingdom

${ }^{4}$ Evidence Response Team Unit, Federal Bureau of Investigation Laboratory Division, Quantico, VA 22135

Journal: Forensic Science International

*Corresponding author; Phone: 703-632-7834; Email: Brian.Eckenrode@ic.fbi.gov 


\begin{abstract}
Effective and reliable training aids for victim recovery canine teams is essential for law enforcement and investigative purposes. Without adequate training aids, the rate of recovery for sub surface or surface human remains deposition using canine teams may be adversely affected and result in confusing information. The composition of three commercially available canine training aids that purportedly generate volatile components responsible for the odor of human decomposition is relatively simple and not closely related to those compounds experimentally determined to be present at the site of surface or sub-surface human remains. In this study, these different commercial formulations were chemically characterized using six different sampling approaches, including two applications of direct liquid injection, solid-phase microextraction (SPME), purge and trap, ambient preconcentration/thermal desorption, and cryogenic preconcentration/thermal desorption. Direct liquid injections resulted in the fewest number of detected compounds, while a cryogen based thermal desorption method detected the greatest number of compounds in each formulation. Based solely upon the direct liquid injection analysis, Pseudo ${ }^{\mathrm{TM}}$ Scent I was composed of approximately $29 \pm 4 \%$ and $71 \pm 5 \%$ of 2 pyrrolidinone and 4-aminobutanoic acid, respectively. This same analysis showed that Pseudo ${ }^{\text {TM }}$ Scent II was composed of approximately $11 \pm 1,11 \pm 1,24 \pm 5$, and $54 \pm 7 \%$ of putrescine, cadaverine, 2-pyrrolidinone, and 4-aminobutanoic acid, respectively. Headspace analysis was conducted to more closely simulate the process whereby a canine's nose would capture a volatiles profile. More compounds were detected using the headspace sampling method; however, the vast majority was not consistent with current data on human decomposition. Additionally, the three formulations were tested in outdoor and indoor scenarios by a doubleblinded canine team, using a certified and specifically trained victim recovery canine with multiple confirmed recoveries, to determine if the formulations would be recognized by that canine as being related to human decomposition. The canine used in this study did not provide a positive response to any of the formulations tested in either test scenario. The implications for locating residual human decomposition odor in the absence of recoverable material are discussed in light of these data.
\end{abstract}




\section{Introduction}

The application of detection canine teams (canine + handler) in law enforcement and military search operations is well-documented [1-5]. Canine resources are used to search for contraband such as drugs [6,7], explosives [8-10], and firearms, and non-contraband such as missing persons [11-13], human remains, clandestine burial sites [14-18], associating crime scene evidence with a suspect [6,11], and tracking and trailing [13-15]. Recently, the role of the canine used in 'no body' homicide and critical-case child abduction investigations has expanded to include locating both residual human decomposition odor in the absence of recoverable material and human blood deposits [19].

Detection canine training programs use various actual and synthetic training aids to train dogs to search for and identify a specific odor or odors. An odor usually consists of one or more volatile compounds that are detected by olfaction. Training aids are used that typically and preferably consist of varying amounts of the actual substances the canine is being trained to find. Within the training paradigm, odor recognition training creates a reproducible behavioral final response on specific substance odor(s) with no trained responses to distractor odors. Ideally, training aids consisting of real substances are used for training canines; for example, specific explosives or combinations of actual explosive materials are used in training to replicate explosive odors and simulate operational scenarios.

Training aids used by the community of canine teams working in victim recovery (VR) to train dogs for locating human remains is quite diverse for a variety of reasons [20]. The acquisition and possession of human remains for canine training is regulated by individual states and sourcing appropriate amounts and types of human remains training aids continues to be difficult. Some handlers acquire human tissue, human bone, odor pads that have been in contact with a deceased subject, or blood from local hospitals, from a medical examiner's office, or from another handler. Some handlers use mimics, such as those sold by Sigma-Aldrich. Commercially available training aids could offer the greatest potential advantage because they could be easily acquired by canine handlers from around the world and provide consistency via precise formulations and appropriate packaging for use in the field. They also could alleviate any ethical concerns which may arise from using actual human tissue, which some states and countries prohibit. 
The development of decomposition odor mimics for training (i.e. training aids), in general, has been undertaken in an attempt to provide a more convenient, safe, and reliable method to train detection canines. Effective mimics should be representative of the actual target volatile organic compound (VOC) profile, representative of the true target odor levels available to the dog under realistic deployment conditions, stable for long periods of time, safe and easy to use, not prone to contamination, and able to consistently produce a canine capable of detecting the desired substance odor without responding to non target substances via proper training [21].

For a training aid mimic to be effective, the key relevant odors of forensic interest must first be identified in order to select the fewest number of target substances needed for optimal training to enhance the capabilities of detector dogs, such as only those VOCs specific to human decomposition [8]. Unfortunately, there is a limited amount of research that characterizes VOCs emanating from human remains specifically and no peer-reviewed data identifying the odor profile(s) used by dogs to locate the odor of human decomposition [22-25]. Identifying the key odors of interest is difficult due to the number of factors that influence both the qualitative and quantitative aspects of the VOCs measured over human remains, both at the soil surface and at specific depths. Temporal effects, such as time since death and decomposition changes over time, disposition of the body (surface, buried, or submerged), environmental factors, and influence of scavengers, soil moisture levels, and clothing can all complicate the odor profile. There are several ongoing studies attempting to ascertain the effect of time since death and the effect of disposition of the remains [26-28]. Developing a training aid that can account for all of these variables is challenging.

From a canine training perspective, the process of VOC generalization is important to consider. This behavioral process of generalization is when a canine trained on various types of a particular substance odor learns to respond to similar untrained odors. In 1999, Johnston determined that when dogs were generalized to smokeless powders in training, they were more likely to respond to a broader spectrum of powders when tested [29]. A study conducted by Harper et al. [8] examined dominant odor chemicals emanating from explosives for use in developing canine training aids and reported wide variability in the measured odor chemicals for smokeless powders from different manufacturers. Canine testing indicated that there was no single low explosive component that elicited responses in a majority of the canines, suggesting that explosive detection canines should be trained on multiple brands of smokeless powders to 
ensure that effective odor chemical profile generalization is achieved. These data also suggest that canines trained on limited varieties of smokeless powders will only allow canines to reliably detect the specific commercial brands on which they were trained.

Similar results to those of Johnston and Harper et al. were observed during human remains analysis and pilot testing of detection canines conducted at the Federal Bureau of Investigation (FBI) research facilities. Non-FBI canine teams were invited to attend, for preliminary evaluation, and it was found that they were training using a limited variety of tissue types for training aids and did not respond to unfamiliar human remains test samples, thus indicating that the teams may not have been sufficiently generalized. As stated by Hoffman et al., [20] the odor chemicals produced by decomposing human remains of various body parts from different human donors show VOC similarities, but sufficient differences exist. Applying the information derived by Johnston, Harper, and Hoffman, training aids from various human tissue types and in differing quantities are most likely needed to adequately generalize a canine to the odor spectrum of decomposing human remains. It is important to note that substituting various human tissue types in lieu of a whole human body, while usually necessary, may result in a different overall VOC profile. However, it is possible that there are a "core" set of VOCs that define human decomposition that may be contained in the various human tissue types. Therefore, it is essential that the canines are trained to generalize within the human specific subset of decomposition in general.

In addition to continuing our efforts in understanding the VOCs emanating from various human tissue types under differing environmental scenarios, this research effort addressed the chemical characterization of commercially available canine training aids, including additional limited and preliminary canine evaluations. The canine evaluations were performed to assess whether a canine trained to discriminate the odor of human specific decomposition would associate and provide a positive response to the commercial training aid odor. It is important to note that this research effort is not about testing the generalization ability of a canine that has been trained on a human decomposition odor mimic to locate a decomposing human or any odors associated with the decomposition of human remains. This is an interesting distinction and reversal of a typical scientific process. The hypothesis here is that a proficient detection dog, when generalized with human remains, will disregard odor distracters and other odors in double- 
blind testing if those odors are outside of the canine's generalization range. This will demonstrate the dog's ability to discriminate human decomposition odor specifically.

This research, which has been ongoing since 2009, describes the chemical characterization of three commercially available synthetic human remains training aids with subsequent canine team evaluation [30,31]. The three training aids examined were: Sigma Pseudo $^{\text {TM }}$ Corpse Scent Formulation I (PSI), Sigma Pseudo ${ }^{\text {TM }}$ Corpse Scent Formulation II (PSII), and Sigma Pseudo ${ }^{\mathrm{TM}}$ Corpse Scent Drowned Victim (PSDV) scent formulation. Each of these synthetic Pseudo Scent mixtures was analyzed via direct injection, headspace solid phase microextraction (SPME), purge and trap, and thermal desorption followed by GC/MS with comparisons to published literature describing the VOCs emanating from both surface and subsurface human remains, as illustrated in Figure 1. There was no intent to compare the results obtained by the various methods and substrates used, as it was expected each method would result in different compounds being observed. Instead, the use of multiple methods was intended to provide a more complete picture of the training aids' chemical makeup and a more comprehensive comparison to the published human remains literature. As such, it is important to note that these training aids are being evaluated in terms of their chemical similarity to those compounds reported in the literature as present at the site of actual human remains.

The development of a functional chemical synthetic mimic to train human remains detection (HRD) canines could result in more widespread standardized practices, an understanding of the compounds required for successful outcomes, and the potential for an increase in the recovery rate of missing homicide victims.

\section{Materials and Methods}

\subsection{Chemicals and reagents}

The canine training aids tested in this work, PSI, PSII and PSDV, were obtained from Sigma-Aldrich (Milwaukee, WI). Multiple lots over the course of several years were tested. Training aid products from other companies were considered; however, the manufacturers were either non-responsive or formulations could not be obtained in time for this study. Chromatography grade methanol, acetone, pentane, methylene chloride, isopropanol, and VOC free water were purchased from Burdick and Jackson (Morristown, NJ). Methanol, acetone, pentane, and methylene chloride were used in liquid-liquid extraction experiments. Cadaverine 
(1,4-butanediamine) and putrescine (1,5-pentanediamine) were obtained from Acros Organics (Geel, Belgium) and used to verify the validity of the sampling methods. Two different types of gauze pads were used: sterile 4" $\times$ 4" 12-ply cotton pads (Dukal Corporation, Hauppauge, NY) and 5" $\times$ 9" Surgipad Surgical dressings (Johnson \& Johnson, Skillman, NJ). Polyurethane tubing ( 0.375 " o.d., 0.25 " i.d.) was obtained from Fisher Scientific (Waltham, MA).

\subsection{Instrumentation, Sample Collection, and Analysis}

2.2.1a Liquid Samples - One Dimensional Analysis (1D)

An Agilent 6890N gas chromatograph (GC) coupled to an Agilent 5973 mass selective detector (MSD) (Agilent Technologies, Palo Alto, CA) was used for the mass spectrometric analysis of PSI, PSII, and PSDV. Separations were performed using a DB5-MS coated fusedsilica capillary column (15 m length x $0.25 \mathrm{~mm}$ ID x $0.25 \mu \mathrm{m}$; J \& W Scientific, Folsom, CA). For analysis of liquid samples, $0.1 \mu \mathrm{L}$ of PSI or PSII was injected in splitless mode with a purge time and flow of 0.50 minutes and $24.7 \mathrm{~mL} / \mathrm{min}$, respectively. The inlet temperature was set at $190^{\circ} \mathrm{C}$. The column pressure was maintained at $2.17 \mathrm{psi}$, which resulted in an average velocity of $57 \mathrm{~cm} / \mathrm{sec}$. A multiple ramp temperature gradient was used to affect the separation of components in each formulation. An initial temperature of $35^{\circ} \mathrm{C}$ was maintained for 1 minute and ramped at $6^{\circ} \mathrm{C} / \mathrm{min}$ to $80^{\circ} \mathrm{C}$, with no hold. The temperature was then ramped at $10^{\circ} \mathrm{C} / \mathrm{min}$ to a temperature of $120^{\circ} \mathrm{C}$, with no hold. Finally, the temperature was ramped at $40^{\circ} \mathrm{C} / \mathrm{min}$ to a final temperature of $260^{\circ} \mathrm{C}$ and held for 2 minutes. The MSD transfer line was held at $250^{\circ} \mathrm{C}$, while the quadrupole and source were maintained at $150^{\circ} \mathrm{C}$ and $230^{\circ} \mathrm{C}$, respectively, with a solvent delay of 2 minutes. Data were collected in full scan mode over the range of 30 to 300 $\mathrm{m} / \mathrm{z}$. All compound identifications for all sampling approaches were made using the NIST Mass Spectral Database.

\subsection{1b Liquid Samples - Two Dimensional Analysis (2D)}

PSI and PSII were also analyzed using a LECO Pegasus 4D GC×GC-TOFMS system (St. Joseph, MI) in the comprehensive GC $\times$ GC mode. The Pegasus 4D employs two columns in series that are separated by a thermal modulator, which enables two-dimensional separations. For these analyses, a Restek RTX-5 column (10 m x 0.18 mm x $0.2 \mu \mathrm{m})$ and a Restek Rxi-17 
column $(1.1 \mathrm{~m} \times 0.10 \mathrm{~mm} \times 0.10 \mu \mathrm{m})$ were used. A multiple ramp temperature gradient was used to affect the separation of components in each sample. An initial temperature of $35^{\circ} \mathrm{C}$ was maintained for 6 minutes and ramped at $6^{\circ} \mathrm{C} / \mathrm{min}$ to $80^{\circ} \mathrm{C}$, with no hold. The temperature was then ramped at $10^{\circ} \mathrm{C} / \mathrm{min}$ to a temperature of $120^{\circ} \mathrm{C}$, with no hold. Finally, the temperature was ramped at $40^{\circ} \mathrm{C} / \mathrm{min}$ to a final temperature of $260^{\circ} \mathrm{C}$ and held for 2 minutes. The secondary oven followed the same temperature gradient, but was held $+25^{\circ} \mathrm{C}$ relative to the main oven. The modulator was held at a temperature $+40^{\circ} \mathrm{C}$ relative to the secondary oven and employed a modulation period and hot pulse time of 3 and 0.50 seconds, respectively. The transfer line was held at $250^{\circ} \mathrm{C}$ with no solvent delay. Data was collected over the mass range of 30 to $300 \mathrm{~m} / \mathrm{z}$ at an acquisition rate of $200 \mathrm{spectra} / \mathrm{s}$.

\subsubsection{Solid Phase Microextraction (SPME)}

Analysis of SPME collected samples was performed using the 1D analytical methodology, with slight modification. The same type of column was used, but the column length was 30 meters. The injection port was raised to $250^{\circ} \mathrm{C}$ and operated in the splitless mode with no purge time and a flow of $24 \mathrm{~mL} / \mathrm{min}$. The SPME fiber was left in the heated inlet for the entire length of the chromatographic run. The column pressure was maintained at 8.81 psi, which resulted in an average velocity of $40 \mathrm{~cm} / \mathrm{sec}$. A multiple ramp temperature gradient, as described in the 1D method, was used to affect the separation of components in each sample, and there was no solvent delay.

SPME sampling of each of the three formulations was performed using three $50 / 30 \mu \mathrm{m}$ StableFlex Divinylbenzene/Carboxen/Polydimethylsiloxane (DVB/CAR/PDMS) coated fibers. DVB/CAR/PDMS fibers were selected because they are designed to collect volatiles and semivolatiles over a wide range of polarity and molecular weight (C3-C20, MW=40-275) while sorbing them at trace levels. All SPME fibers used in this work were obtained from Supelco (Supelco, Bellefonte, PA). Fibers were conditioned prior to use for 60 minutes at $270^{\circ} \mathrm{C}$. Fibers were also verified as clean by running the fiber on the instrument at the beginning of each day of sampling. SPME analysis was performed over J\&J gauze pads treated with an entire ampoule of PSI and PSII, which were placed in $40 \mathrm{~mL}$ volatile organic analysis (VOA) vials. The pad and headspace equilibrated overnight at room temperature prior to SPME sampling, and untreated gauze pads were used as negative controls. The PSDV sample was prepared by mixing one 
capsule with $10 \mathrm{~mL}$ of water in a VOA vial, and $10 \mathrm{~mL}$ of water with no capsule was used as a negative control. Each of the formulation samples and the controls were exposed to a SPME fiber, in triplicate, for 16 hours.

\subsubsection{Purge and Trap (P/T)}

$\mathrm{P} / \mathrm{T}$ analysis was performed using a model 4560 purge-and-trap sample concentrator (OI Analytical, College Station, TX) interfaced to an Agilent 6890 GC/5973 MSD. An RTX-VMS column (30 m x 0.25 mm x $1.4 \mu \mathrm{m}$; Restek Corporation, Bellefonte, PA) was used for analyte separation. The GC injector temperature was held at $200^{\circ} \mathrm{C}$ and the MSD transfer line was held at $220^{\circ} \mathrm{C}$. The column flow rate was set at $1.0 \mathrm{~mL} / \mathrm{min}$ when the column was at $40^{\circ} \mathrm{C}$ using a head pressure of approximately $7.0 \mathrm{psi}$. The GC was operated in constant pressure mode during the run and injections were performed in split mode (20:1) with no solvent delay. The oven temperature program utilized was similar to the $1 \mathrm{D}$ method, except that the final temperature was $240^{\circ} \mathrm{C}$ and was held for 4 minutes.

P/T analysis was performed on Dukal gauze pads spiked with $300 \mu \mathrm{L}$ of PSI or PSII, followed by a 45 minute dry helium purge. The PSDV sample was analyzed by dissolving the powder capsule in clean VOC free P/T water $(5 \mathrm{~mL})$. Samples were then purged for 1-3 hours and trapped on Tenax TA® (OI Trap \#7) held at room temperature. Analytes were desorbed from the OI trap at $180^{\circ} \mathrm{C}$ for 4 minutes, after which time the trap was cleaned at $190^{\circ} \mathrm{C}$ for 10 minutes. Extended bakes of the OI heated zones, mechanical cleaning of the sample chamber, and post run blanks were all performed to check for carryover and prepare the instrument for the next sample.

\subsubsection{VOC Sampling with Ambient Preconcentration and Thermal Desorption}

Traditional thermal desorption experiments were conducted using an Automated Chemical Environment Monitor (ACEM) Model 9305 pre-concentration module (CDS Analytical, Inc., Oxford, PA) interfaced to a low thermal mass gas chromatograph/mass spectrometer (LTM-GC/MS) (RVM Scientific, Santa Barbara, CA). The LTM-GC/MS is a modified Agilent 6890N GC, in which the traditional column inside the oven compartment has been replaced with a door mounted LTM column and an external controller module coupled to a 5973 MSD [32]. ${ }^{32}$ Analyses using the LTM-GC/MS system utilized a RTX-5MS coated column 
(30 m length x $0.25 \mathrm{~mm}$ ID x $0.25 \mu \mathrm{m}$; RVM Scientific, Santa Barbara, CA) to perform separations. The oven temperature program utilized was similar to the $1 \mathrm{D}$ method, except that the initial temperature was $40^{\circ} \mathrm{C}$ and a final temperature of $220^{\circ} \mathrm{C}$ was achieved using a ramp of $25^{\circ} \mathrm{C} / \mathrm{min}$. The ACEM 9305 employs an adsorbent-packed high capacity sample tube and a capillary bore focusing trap in series. Both the sample tube and focusing trap were packed with Tenax $\mathrm{TA}^{\circledR}$ 20:35 adsorbent materials.

Samples were prepared for analysis via two methods. In the first method, an entire ampoule containing the appropriate formulation was placed in a $40 \mathrm{~mL}$ VOA vial and allowed to equilibrate for approximately 16 hours before being sampled. In the second method, an entire Dukal gauze pad was folded and placed inside of a $40 \mathrm{~mL}$ VOA vial, upon which a $300 \mu \mathrm{L}$ aliquot of each respective formulation was delivered. The vial headspace was then sampled within 30 seconds of the sample being delivered. At the appropriate time in the method, a helium purge of the headspace was achieved at a flow rate of $0.25 \mathrm{~L} / \mathrm{min}$ for 5.4 minutes onto the tube of the ACEM unit. The tube was then dried via helium flow for 1 minute, followed by heating at $250^{\circ} \mathrm{C}$ for 3 minutes, which desorbed any VOCs onto a focusing trap held at $35^{\circ} \mathrm{C}$. The trap was then heated to $250^{\circ} \mathrm{C}$ for 3 minutes, which flushed the adsorbed material in the trap to the head of the LTM-GC/MS column via a $1 \mathrm{~m}$ transfer line held at $225^{\circ} \mathrm{C}$. No solvent delay was used in this method. For the PSDV samples, a capsule was dissolved in $10 \mathrm{~mL}$ of water and sampled in the same manner as described above for the other samples. A blank piece of gauze was used as a control sample and analyzed by the same method. A volume of $10 \mathrm{~mL}$ of water was used as the control sample for the PSDV samples. The sampling time was selected to provide approximately the same sampled volume as in the purge-and-trap analysis described above so that a comparison between the two methods could be made.

\subsubsection{Cryogenic Preconcentration}

Cryogenic preconcentration experiments were conducted using an Entech 7100A preconcentrator (Simi Valley, CA) interfaced to a LECO Pegasus 4D. The 7100A is composed of three stages of concentration: an empty trap, followed by a Tenax packed trap, followed by another empty trap. Samples are cryofocused on the first trap via a $200 \mathrm{~mL} / \mathrm{min}$ flow at a temperature of $-150^{\circ} \mathrm{C}$. Once the desired volume has been sampled, a cold trap dehydration step is performed by subjecting the first trap to a $75 \mathrm{~mL}$ volume of helium at $100 \mathrm{~mL} / \mathrm{min}$ to reduce 
the amount of water that was trapped. At that time, the Tenax packed trap is cooled to $-50^{\circ} \mathrm{C}$. The first trap is then heated to $40^{\circ} \mathrm{C}$ and $40 \mathrm{~mL}$ of sample is passed to the second trap at a flow of $10 \mathrm{~mL} / \mathrm{min}$. Once the transfer of sample from the first to second trap is complete, the third trap is cooled to $-160^{\circ} \mathrm{C}$. The VOCs collected on the Tenax trap are then passed to the third trap by heating to $180^{\circ} \mathrm{C}$ for 3.5 minutes. The final trap is then heated to $90^{\circ} \mathrm{C}$ and the trapped VOCs are passed through a $1 \mathrm{~m}$ heated transfer line and injected directly into the Pegasus 4D. For these analyses, a RTX-VMS column (30 m x $0.25 \mathrm{~mm}$ x $1.4 \mu \mathrm{m})$ and the Restek Rxi-17 column (1.1 m x $0.10 \mathrm{~mm}$ x $0.10 \mu \mathrm{m}$ ) were used; however, the comprehensive GCxGC mode was not used. An initial temperature of $35^{\circ} \mathrm{C}$ was maintained for 4 minutes and ramped at $4{ }^{\circ} \mathrm{C} / \mathrm{min}$ to $50^{\circ} \mathrm{C}$, with a 2 minute hold. The temperature was then ramped at $10^{\circ} \mathrm{C} / \mathrm{min}$ to a final temperature of $220^{\circ} \mathrm{C}$ and held for 5 minutes. The secondary oven followed the same temperature gradient, but was held $+15^{\circ} \mathrm{C}$ relative to the main oven. The modulator was held at a temperature $+30^{\circ} \mathrm{C}$ relative to the secondary oven. The transfer line was held at $250^{\circ} \mathrm{C}$ and no solvent delay was used. Data was collected over the mass range of 30 to $350 \mathrm{~m} / \mathrm{z}$ at an acquisition rate of $10 \mathrm{spectra} / \mathrm{s}$.

PSI and PSII samples were prepared by placing the entire contents of the ampoule onto a Dukal gauze pad that was folded and placed inside of a $40 \mathrm{~mL}$ VOA vial. A $400 \mathrm{~mL}$ evacuated air sampling canister was then used to immediately collect the headspace from inside and slightly around the VOA vial. The air canister was then attached to the appropriate sampling line on the 7100A, which removed a $200 \mathrm{~mL}$ sample for cryofocusing onto the first trap. Control measurements were made in the same manner, using a blank gauze pad. PSDV samples were prepared by dissolving a capsule in $10 \mathrm{~mL}$ of water inside of a $40 \mathrm{~mL}$ VOA vial. The prepared sample was then collected and analyzed in the same manner as described above for the other samples. A volume of $10 \mathrm{~mL}$ of water was used as the control sample for the PSDV samples.

\subsection{Canine Tests and Evaluation}

Canine team double-blind field testing using the Sigma-Aldrich training aids was conducted to observe and assess if a canine, sufficiently generalized to the odor of human decomposition and with multiple whole body and trace evidence recoveries, responds to PSI, PSII, and PSDV in simulated operational searches. The VR canine team consisted of a canine handler / trainer with over 30 years experience and a certified victim recovery canine with multiple confirmed recoveries. The canine, named Morse, is a 6-year-old male English Springer 
Spaniel. The canine is trained to provide an audible bark as a final response to a wide spectrum of human decomposition odor at differing threshold levels (odor generalization). Canine and handler team proficiency testing includes, but is not limited to, annual certification to meet or exceed Scientific Working Group on Dog and Orthogonal detector Guidelines (SWGDOG) standards [33]. Testing includes blind (to the handler) and double-blind (to both the handler and observer) operational scenario-based searches and laboratory line up screening. The testing includes distracter odors, negative search areas, and blank controls. Canine Morse's initial training involved operant conditioning [17] to discriminate human decomposition odor using training aids that were prepared and utilized with the inclusion of known blank controls and odor distracters. The VR training aids consisted of sterile gauze pads that were placed on a wide variety of recently deceased humans in morgue settings. All training and operational canine / handler team protocols are executed off lead (i.e., no leash is attached to the canine), which diminishes potential handler cueing. Training aids included within the canine's maintenance training regimen consist of a wide variety of human decomposition odor sources encompassing human material, direct contact odor absorbing pads, non contact odor adsorbing pads, and liquid samples prepared in the laboratory by the collection of water which had passed over and through human tissue within a soil-based biotope [34]. Comprehensive operational, proficiency testing, and training records are retained for the purpose of legal procedure and research. PSI, PSII, or PSDV were not used within the training regimen for this canine team. At the time of this research, Morse was the only canine with the required specifications and proficiency level available.

Canine testing of PSI, PSII, and PSDV was conducted in two different settings: outdoors and indoors. In the outdoor setting, the sample sites were selected to be about 12 meters apart along a path near the shoreline of a small lake in Locust Shade Park, Dumfries, VA (see Figure 2a). It was a warm sunny day, approximately $22^{\circ} \mathrm{C}$, with a slight wind. Six samples were numbered sequentially and randomly selected for each sample location along the path. Each sample was applied "wet" on a rock located along the path, with the exception being the PSDV sample. Two capsules of PSDV were placed into the lake, within 1 meter of the shoreline. In addition to PSI, PSII, and PSDV, three other samples were used: (1) 1mL of distilled water was used as a negative control, (2) approximately $1 \mathrm{~mL}$ of a mixture of homogenized human adipose tissue/distilled water was used as the positive control, and (3) $1 \mathrm{~mL}$ of isopropyl alcohol was used 
as a distracter odor. Entire ampoules, $1 \mathrm{~mL}$ each, of PSI and PSII were used, while both a crushed tablet and whole tablet of PSDV were used. The positive control location was placed as the last questioned sample in the sample line-up along the shore so that any wind present during the testing was always moving toward it so the odor from the positive control was not drifting toward the other samples. Pre-testing of the positive controls was successfully performed by the canine team. Samples were placed as described above, and the double-blind field testing was initiated with the test being completed in about 10 minutes.

In the second setting, the canine team conducted indoor odor discrimination tests. For PSI and PSII formulation evaluations, double blind testing used five odor screening stations approximately 2 meters apart within a purpose built facility (see Figure $2 b$ ). Each screening station consisted of two perforated metal cans suspended less that 1 meter off of the floor by a metal stand. For PSI and PSII, a gauze pad was impregnated with approximately $1 \mathrm{~mL}$ of sample and placed within the appropriate randomly determined metal can. In some cases, a can was left empty or held a blank gauze pad to serve as a blank. Negative controls consisted of water and pads with various odors on them (i.e. handler odor, pad collected from office area, pad collected from gym, pad collected from kitchen, etc). The facility is equipped with air handlers designed to completely purge the volume of air within the room in a matter of minutes. Of the five available stations (10 perforated cans) in each screening run, the application and position of odors included $1 \mathrm{~mL}$ of isopropanol as a distracter odor, $1 \mathrm{~mL}$ test samples, $1 \mathrm{~mL}$ of the homogenized human adipose tissue/water mixture as a positive control and $1 \mathrm{~mL}$ of water as a negative control. In each of the 5 trials, one can contained one pad impregnated with an appropriate amount of sample and all the others were either distracters, blank, or empty (Figure 3, 1-5). Between trials, sample cans were washed via an established cleaning protocol and in some trials a new sample can was used to avoid any possible cross-over contamination. The samples used, as well as their placement within the 5 screening stations, were decided by a random number generator. Pre-testing of the positive controls was successfully performed by the canine team.

The screening of liquids, or in this case PSDV, is facilitated by replacing the screening stations with receptacles appropriate to the type of research being conducted. In this case, ten 19L buckets filled with approximately $15 \mathrm{~L}$ of tap water were used to contain the samples. A variety of foodstuffs were used as distracters. Approximately $20 \mathrm{~mL}$ of each of the distracters 
was added separately to a specifically numbered bucket. Tap water with no additive was used as a negative control and $20 \mathrm{~mL}$ of isopropanol was added to one of the buckets as a pungent distracter. All of these samples were randomly placed in the room, along with the PSDV capsule containing bucket, for a total of three trials (Figure 3, 6-8). Pre-testing of the positive controls was successfully performed by the canine team.

\section{Results and Discussion}

The comprehensive chemical analysis discussed below, followed by double-blind field testing and evaluation with a canine team, for the commercially available pseudo scents evaluated in this research, will help to ascertain the efficacy of these particular formulations, while shedding light on the overall mimic evaluation process and the resulting research implications therein.

\subsection{Liquid Injections}

Multiple injections into a GC/MS were made of each formulation and Figure 4a-c illustrates the representative total ion current (TIC) chromatograms for each formulation when analyzed in this manner. The liquid injections indicate that each formulation consists of only a few compounds. PSI is intended to mimic fresh decomposition and has the fewest observed compounds. Two dominant peaks were identified: 2-pyrrolidinone and 4-aminobutanoic acid. Assuming these compounds make up $99 \%$ of the total peak area present, the percent composition of PSI was determined to be approximately $28 \pm 4 \%$ and $71 \pm 5 \%$ of 2-pyrrolidinone and 4aminobutanoic acid, respectively. There were two very small peaks observed in the formulation which typically accounted for approximately $1 \%$ of the total peak area. These components, 3methyl-2-pyrrolidinone and 4-methyl-2-pyrrolidinone, are believed to be impurities or byproducts of the major constituents of the formulation. As shown in Figure 4, considerable peak fronting is observed for the major constituents and split injections of the same volume at a 20:1 ratio resulted in similar peak shapes. This may be due to the non-polar and polar structural characteristics of these compounds, in combination with their high relative concentrations in the liquid phase. One other interesting note is that upon thermal activation, 4-aminobutanoic acid can eliminate water and form 2-pyrrolidinone (see inset Figure 4a) [35]. This may also contribute to the observed peak fronting due to the elimination reaction occurring in the injector 
and temporally and/or spatially spreading the components onto the GC column phase. Based upon published research of the compounds found at two different sites of buried bodies, neither of the two predominant components of PSI have been observed in either soil or air samples at those sites [20, 25]. Additionally, these compounds have never been reported around surface human decomposition $[22,23]$.

PSII consists of only a slightly more complex composition than PSI, as shown in Figure 4b. There were two additional compounds observed: 1,4-butanediamine and 1,5pentanediamine, also known as putrescine and cadaverine, respectively. Putrescine and cadaverine are similar to those compounds created during the decomposition of organic matter [17]. According to Dent et al, putrescine and cadaverine are prominent decarboxylation products of proteins and should be present at the site of human remains [36]. Assuming that these compounds make up $99 \%$ of the total peak area present, the approximate percent composition of PSII was $11 \pm 1 \%, 11 \pm 1 \%, 24 \pm 5 \%$, and $54 \pm 7 \%$ of putrescine, cadaverine, 2-pyrrolidinone, and 4-aminobutanoic acid, respectively. It appears that the amount of 4-aminobutanoic acid in the formulation was reduced to accommodate the addition of putrescine and cadaverine. There were also two very small peaks observed in this formulation, corresponding to the same minor peaks found in PSI. It was observed that the variance is much lower for both putrescine and cadaverine than it was for either 2-pyrrolidinone or 4-aminobutanoic acid. This indicates that any reproducibility issues observed in PSI and PSII for 2-pyrrolidinone and 4-aminobutanoic specifically, is most likely not instrumental in nature. Putrescine and cadaverine also exhibit much better peak shapes, again indicating that the poor peak shapes observed with 2pyrrolidinone and 4-aminobutanoic acid are compound specific and not solely instrumental. There are various explanations given in the literature as to why the VOCs putrescine and cadaverine have not been observed at the site of human remains, ranging from lack of volatility to thermal lability [24]. It has also been observed that putrescine can be metabolized to form 5hydroxy-2-pyrrolidone and 2-pyrrolidone and upon decomposition may form salts, thereby making them non-volatile [37, 38]. However, we were able to detect and identify these compounds in the liquid injections without derivatization, as well as in SPME samples and headspace samples when sampling from a container with several milliliters of neat putrescine and cadaverine. This indicates that there is no instrumental reason why these compounds would not be detected by our analytical procedure. 
The analysis of PSDV was not nearly as straightforward as for the other two formulations. Because this formulation is purchased as a powder to be dissolved in water, a direct liquid injection of the received material was not feasible. Instead, an aliquot of the water in which the powder was dissolved, was analyzed. This analysis showed results similar to that of PSI. Again, there were the same two predominant components identified: 2-pyrrolidinone and 4aminobutanoic acid as shown in Figure 4c. However, this is not surprising, as both of these compounds are water soluble. When a capsule of PSDV is placed in water, it works by forming a thin layer of organic material on the surface of the water that slowly volatilizes into the atmosphere. In an attempt to collect this thin layer, a liquid-liquid extraction of PSDV dissolved in water was performed using methanol, pentane, or methylene chloride, independently. Analysis of each of these differently extracted fractions did not reveal any additional compounds. It should be noted that the manufacturer's Material Safety Data Sheet (Version 3.0, 10/27/2009) for PSDV lists 4-aminobutanoic acid (11.8\%) and $\mathrm{NaCl}(88.2 \%)$ as the sole constituents.

Comprehensive GC $\times$ GC-TOF-MS was used to determine if the overly broad peaks observed previously were obscuring other compounds. Analysis of both PSI and PSII was performed using GC $\times$ GC-TOF-MS, as described in Section 2.2.1.b. The analysis of PSII, shown in Figure 5, indicates this analysis yielded fairly similar results to those previously obtained using 1D GC/MS; however, several additional compounds were observed. For PSI, small amounts of acetone and isopropanol were also observed and for PSII, 5-amino-pentanol, ethanol, butyrolactone, acetone, methanol, and 1,4-dioxane were also observed at low relative levels. Both acetone and ethanol have been reported to be present at the site of human remains. Compositional analysis was not performed, nor was any analysis of PSDV attempted using this method. In 2011, Stadler et al. used comprehensive GC $\times$ GC to characterize the formulations tested in this work [39]. The compounds they observed are in good agreement with the compounds reported here.

\subsection{SPME Analysis}

Each of the three formulations was also analyzed with static SPME sampling as described in Section 2.2.2. The sampling time used is much greater than the amount of time a canine would need to sample a formulation loaded pad, but necessary to provide for the establishment of equilibrium for components that may be present at trace levels. Canines sample in a dynamic, 
flow through fashion at a total airflow rate of roughly $60 \mathrm{ml} / \mathrm{sec}$ at very close proximity to a test item or target during normal odor recognition [40]. Results compiled from triplicate SPME analyses of each formulation yielded numerous components and Figure 6 shows the TIC chromatograms for each of the formulations tested. Compounds were only reported if they were found in all three TIC chromatograms and also determined to be either absent or of significantly lower total signal in the TIC chromatogram of the control, based upon the average total signal of the sample when compared to the average total signal of the control. In the latter case, the average total signal of any such component in the TIC chromatogram of the control was subtracted from the average total signal of that component in the TIC chromatogram of the sample. SPME sampling of the three formulations resulted in the measurement of 18 VOCs for PSI, 16 VOCs for PSII, and 15 VOCs for PSDV (see Table 1).

Analysis of PSI revealed that 2-methyl-1-(1,1-dimethylethyl)-2-methyl-1,3-propanediyl propanoic acid (MDMPP) and acetone were present, comprising roughly $42 \%$ of the total peak area. It is interesting to note that MDMPP has been observed in human breath [41]. Benzophenone and 1-butanol were observed at moderate levels, both comprising about $28 \%$ of the total peak area. Also present at low levels was 2-ethyl-1-hexanol. Based upon the published literature, 1-butanol has been observed at the site of human remains, as were several other compounds observed here: 2-butanone, heptane, octane, and hexanal [20, 22, 24]. These additional compounds were observed at low levels and were not major contributors to the overall signal.

Analysis of PSII indicated MDMPP as the major component, with approximately $27 \%$ of the total peak area. The presence of 2-ethyl-1-hexanol, benzophenone, 2,4,6-trimethyl-pyridine, and acetone at moderate levels was also observed. The presence of 2-ethyl-1-hexanol has been observed at the site of human remains. Additionally, 2-heptanone was observed, which was reported in the literature to be present at the site of human remains [22, 23]. Another compound of interest that was observed, not related to human remains VOCs, was 1,4-dioxane. The presence of 1,4-dioxane, believed to be a contaminant in putrescine or cadaverine, should be noted, as it may be harmful to canines.

Analysis of PSDV indicated that small amounts of 2-ethyl-1-hexanol, 2-butanone, 3heptanone, 3-pentanone, and 2,4-bis(1,1-dimethyl)-phenol were present. These five compounds accounted for approximately $41 \%$ of the total peak area. As observed in PSI and/or PSII, 2- 
butanone, 2-ethyl-1-hexanol, and 2-heptanone were observed, which have been found to be present at the site of human remains.

\subsection{Purge and Trap (P/T) Injections}

The P/T of a Dukal gauze pad loaded with PSI or PSII yielded a limited number of compounds that could be detected. Acetone accounted for $93 \pm 3 \%(\mathrm{n}=3$ gauze) of the total detectable analyte signal purged from PSI, while isopropanol and 2-butanone accounted for $1.7 \pm$ $0.1 \%$ and $1.3 \pm 0.2 \%(\mathrm{n}=3$ gauze both analytes), respectively. The P/T analysis of VOCs from PSII was more informative, liberating eleven compounds; primarily alcohols and aldehydes, from $\mathrm{C}_{4}$ to $\mathrm{C}_{10}$. Of the eleven compounds identified, four were highly conserved and when taken together constituted $80 \%$ of the total liberated VOC signal. Acetone, 1-vinyl aziridine, 1,4dioxane, and 1-pentanol constituted $19 \pm 2 \%, 28 \pm 6 \%, 14 \pm 3 \%$, and $28 \pm 10 \%$ (n = 3 gauze) respectively, of the total VOC signal measured from the gauze pad via P/T analysis. 1-pentanol has been reported as being at the site of human remains. When an entire capsule of PSDV was dissolved in VOC free P/T water, a 90/10 ratio of ethanol and ethyl butyrate was liberated when purged with helium for 1-3 hours. Ethyl butyrate has been reported as being observed at the site of human remains. There was no change in the number of compounds present in the profile, nor did the ratio of ethanol and ethyl butyrate change as the purge time was increased to 3 hours.

\subsection{ACEM Injections}

ACEM headspace analysis of PSI using conventional thermal desorption tubes and traps revealed different compounds than the other methods. Both ACEM sampling methods identified acetone as a key component of the formulation. The headspace above PSI also indicated the presence of $\alpha$-methylstyrene, acetophenone, nonadecane, and a phthalate. The volatiles observed from a vial containing the PSI loaded gauze pad were 2-butanone, 2-pentanone, 3methyl-2-pentanone, heptanal, and 2-butoxyethanol. Of these, only 2-pentanone and heptanal have been reported as being observed at the site of human remains. Representative TIC chromatograms from the ACEM experiments on the formulation loaded pads are shown in Figure 7. It is interesting to note that none of the compounds observed in the analysis of the liquid sample were observed in the headspace analysis. This is not entirely surprising for 2- 
pyrrolidinone and 4-aminobutanoic acid, given that both of these compounds have relatively low vapor pressures $\left(0.008 \mathrm{~mm} \mathrm{Hg}\right.$ at $25^{\circ} \mathrm{C}$ and $9.02 \mathrm{E}-05 \mathrm{mmHg}$ at $25^{\circ} \mathrm{C}$, respectively).

ACEM analysis of PSII revealed different compounds than the liquid injection of the same formulation. Both ACEM methods again identified acetone as a component. In addition, both methods identified 2-butanone, 1-butanol, 1,4-dioxane, 1-pentanol, and 2,3,4,5tetrahydropyridazine. The headspace above the liquid PSII also showed the presence of $\alpha$ methylstyrene, acetophenone, diphenyl sulfone, and a high molecular weight phthalate. The additional volatiles observed from the vial containing the formulation treated gauze pad were 3 methyl-2-pentanone and 2-cyclopenten-1-one. As noted above, none of the compounds observed in the liquid sample were observed in the headspace analysis. This is more surprising in this case due to the significant signal measured and the relatively high vapor pressure of both putrescine and cadaverine, which were expected to be observed by this analysis. To investigate this further, several milliliters of a putrescine/cadaverine mix (approximately 50:50 by volume) were placed in a $40 \mathrm{~mL}$ VOA vial and analyzed as above resulting in very pronounced peaks for both putrescine and cadaverine. In addition, 1-pentanol and 1,4-dioxane were present, indicating that their presence in PSII is a breakdown product or contaminant in putrescine and/or cadaverine. From this result, it is clear that the methodology utilized here is capable of detecting these two compounds. The lack of their presence in the headspace above PSII may indicate that despite having appreciable vapor pressures, they are tightly bound by the other components that are at much higher levels in the formulation and perhaps could be the result of a co-solvency effect. All of the components observed in the liquid PSII are amines, with putrescine and cadaverine both being diamines.

ACEM analysis of PSDV revealed relatively few compounds and because of the nature of the material, only a liquid sample was analyzed. The analysis of this liquid sample resulted in the identification of $\alpha$-methylstyrene and ethyl butyrate. This finding is very surprising based upon the manner in which this formulation is supposed to work. Depending upon the specific environmental conditions under which it is used, the scent plume that is created is reported by the manufacturer to last up to 45 minutes. Under the conditions used here, utilizing a well contained environment, it was expected that numerous organic compounds would be observed.

\subsection{Cryogenic Preconcentrator Analysis}


This method of sample collection is the closest "sampling time" simulation in terms of how long a canine would actually smell or sample a training aid during a field trial. However, it should be noted that a canine would sample a much greater volume of air from around a training aid than what was sampled here. As discussed earlier, Settles and Kester determined that the average canine samples at approximately $3.6 \mathrm{~L} / \mathrm{min}$ [40] and assuming a canine would do so for approximately 30 seconds, a volume of $1800 \mathrm{~mL}$ would have been sampled. This is a factor of nearly 10 more than was sampled using the procedure described here.

Analysis of the PSI loaded gauze pad indicated a total of 83 compounds. Two compounds, acetone and isopropanol, were the major contributors to the overall signal and accounted for approximately $86 \%$ of the total signal. There were only three other compounds whose contributions each accounted for greater than $1 \%$ of the signal: ethanol $(4.5 \%), 1,1$ difluoroethane $(2.9 \%)$, and octane $(1.2 \%)$.

Analysis of the PSII loaded gauze pad indicated a total of 77 compounds. The analysis showed that two compounds, acetone and ethanol, were the major contributors to the overall signal, accounting for approximately $62 \%$ of the total signal. There were an additional 7 compounds that each contributed at least $1 \%$ of the total signal: 1,4-dioxane (4.4\%), pentyl ester of formic acid (3.6\%), 1-bromo-2-propanol (2.7\%), 2-butanone $(2.2 \%), \quad 3,4$ dimethyldihydrofuran-2,5-dione (1.2\%), acetaldehyde (1.1\%), and 2-amino-1-propanol (1.0\%), with acetaldehyde being previously observed at the site of human remains.

Analysis of the PSDV indicated a total of 49 compounds. Two compounds, ethanol and propene, were the major contributors to the overall signal, accounting for approximately $42 \%$ of the total signal. There were an additional 17 compounds that each contributed at least $1 \%$ of the total signal, including: 1,2-propanediamine (7.3\%), nonanal $(3.2 \%)$, cyclobutylamine $(2.7 \%)$, and carbon disulfide (1.4\%). These compounds have either been associated with or are similar to other compounds associated with human remains.

\subsection{VOC Comparison to Published Literature}

In this study, there were 70 different compounds observed across all of the different sampling and analysis methods. Only 23 of them have been measured at the site of human remains based upon the published literature and 15 of these were found in this study to be 
present at levels just above baseline ( $1 \%$ of their respective TICs). The remaining 8 were measured at even lower levels and were not specifically identified here. Furthermore, of the 23 compounds found in the literature, 7 of those were listed in only one of the several previously published reports, indicating that there is some disparity throughout the literature in defining the VOCs associated with human decomposition. Finally, only 4 of the 23 compounds listed thus far have been observed in $50 \%$ or more of the previously published reports, indicating that these 4 may hold a greater relevance for their inclusion as reproducible human decomposition VOCs. These 4 compounds were 2-ethyl-1-hexanol, carbon disulfide, hexanal, and nonanal, with hexanal being present at less than $1 \%$ of the TIC in which it was observed.

\subsection{Canine Tests and Evaluation}

The canine testing methodology used in this research is primarily optimized for no-body homicide or critical child abduction investigational situations where there may only be human decomposition odor present. Since the chemical analysis of these formulations yielded only a fraction of the chemicals found in the literature to be associated with human decomposition, a decision was made to pursue a canine testing methodology utilizing the most appropriate K9 resource available at that time. An alternative experimental design was considered to statistically test several appropriate canines that would be trained exclusively on the pseudo scent formulations. The results of experiments conducted in this manner would be difficult to interpret due to a variety of reasons and would not be cost effective for the FBI. As a result of these considerations, the methods described here use an approach whereby a canine trained specifically to known human decomposition odor is tested in a double-blind fashion to yield a positive or negative response to test mimics.

The detection canine, Morse, has been extensively blind and double blind proficiency and odor recognition tested under controlled conditions with multiple recoveries in operational settings. The outdoor canine scenario in this study was chosen to simulate an actual operational setting (see Figure 2a). The canine team performed a pre-test using the human adipose tissue/water mixture as a positive control to verify that the team was working properly before the actual testing scenario commenced. The canine provided the appropriate positive response to this adipose sample. Six samples were then placed, as described in the materials and methods 
section, in the following order: PSII, isopropanol, PSDV, water, PSI, and the positive control. The canine showed no interest in or positive responses to the first five samples. However, there was a positive response at the area where the positive control was placed. This clearly indicates that the canine used in these tests, a certified canine with a history of locating human remains, does not associate any of the three formulations with human remains odor. In other words, the tested VR canine that was trained on human decomposition odor with demonstrated generalization capabilities, did not provide a positive response to the chemical mixture of the pseudo scent products.

Several weeks following the outdoor scenario and with the same canine team, further testing was conducted in an indoor laboratory setting, so that environmental conditions could be more tightly controlled. The facility used was specially designed for performing odor discrimination using canine teams. As in the outdoor test, the positive control was used to verify that the team was working properly before the testing scenario commenced. In this set of experiments, different samples were placed on gauze pads, as described in the materials and methods section. Each trial, of which there were five total for PS1 and PSII testing, consisted of 5 possible randomized samples: positive control, negative control, distracter, and PSI and PSII formulations. The first two of the five trials consisted of negative controls only and resulted in negative responses. The third trial included the positive control, which resulted in a canine positive response. The fourth and fifth trials included PSI and PSII, respectively, and did not result in any positive responses from the canine.

The PSDV testing was performed in an adjoining room that contained ten 5-gallon buckets filled with water and included various distracters described in the materials and methods section. During pretesting, a positive control was placed throughout a 10 bucket test scenario in a random fashion and the canine provided a positive response on the positive control bucket only. In three separate and similar trials thereafter, with the PSDV sample randomly placed, the canine did not provide a positive response to any of the buckets.

\section{Conclusions}

The scientific literature contains reports of many compounds being produced during the human decomposition process. To create an effective mimic, VOCs common to all forms of human decomposition and their relative ratios should be identified analytically prior to any 
canine testing. Ideally, the VOCs would be present immediately post-mortem and remain unchanged throughout the decomposition process, while not being present in animal decomposition at the specific relative ratios or naturally found in the environment at the same relative ratios. It is not known whether human decomposition odor is interpreted (recognized and discriminated) by the canine as a generic odor with consistent relative ratios of VOCs, whether there is one single compound that is created at the moment of death that remains detectible by the canine throughout full decomposition, whether each stage of decomposition has its own distinct odor profile, whether sub-surface or surface VOC profiles have common compounds, or if there is a suite of chemicals that when combined in appropriate ratios will represent the human decomposition odor as best as we can provide for canine training. Once researchers identify the compound(s) and their relative ratios believed important for detection, canines trained only on actual human remains, generalized to the odor of human decomposition and with a proven record demonstrating their ability to locate decomposing human remains, should be tested on the synthetic mixtures or single components to determine which, if any, elicit positive responses. Once the synthetic mixture or single component is determined to elicit a positive response by appropriately selected canines and also does not occur regularly in the environment, then canines should be trained solely on the synthetic mixture or single component followed by rigorous field testing to deduce whether the mimic conditions for the canine are sufficient to help them generalize the odor of human decomposition and does not cause the canine to positively respond to pungent non-human decomposition related odors.

This study has examined and evaluated the chemical composition of commercially available human decomposition mimics, Pseudo ${ }^{\text {TM }}$ Scent I, Pseudo ${ }^{\text {TM }}$ Scent II, and Drowning Victim Pseudo Scent. These commercially available canine training aids were analyzed by six different sample introduction techniques. Two techniques analyzed the bulk liquid as a whole, while the other four analyzed the VOCs emanating from the bulk liquids. Characterization of the headspace VOCs was performed for each of the formulations to simulate what a canine may encounter in field scenarios where these compounds would be potentially found during training on positive controls. One of the goals of this research effort was to determine if compounds observed at actual human burial sites are also present in the commercially manufactured training aids studied. Based on published reports of the VOCs found both at ground level, above buried remains, and around surface remains, very few of those compounds were observed in an analysis 
of these commercial training aids. There may be various reasons for this observed difference, for example, the current instrumentation may not be as sensitive as canines, or that there were variations between what was found in the analyzed liquids and what was found in the headspace emanating from those liquids. Certain key compounds, putrescine and cadaverine, long thought to be an important factor at the site of human remains and important in the identification of remains by canines, were not found to be present at detectable levels among the headspace volatiles observed in this study. The chemical composition of the formulations tested tends to show that they are dissimilar to the reported VOCs associated with human decomposition odor.

In summary, this research explored the chemical composition of three pseudo scent formulations for comparison to known human decomposition byproducts and determined whether or not these formulations would elicit any response from a canine that reliably discriminates the odor of human decomposition. In the limited and preliminary canine testing phase of this research, Morse did not provide a positive response to any of the formulations. It is our conclusion that canines trained exclusively with the use of these formulations might not locate human decomposition odor or the canines may provide positive responses to a range of decomposing material and other pungent odors.

Nevertheless, a properly developed human decomposition mimic could be highly beneficial to the canine community in that it would alleviate many training aid integrity issues. The difficulties surrounding the acquisition, storage, and handling of human body parts would be reduced or eliminated. Mimics could be used to minimize inadvertent cues that are sometimes present during training, such as disturbed soil. If mimics are to be used to train VR canine teams, they must be composed of the appropriate compounds at approximately their naturally occurring concentrations or relative ratios. As the mimics are developed, canines will need to be trained solely on mimic odor profiles and tested thoroughly to determine if the canines can find actual human remains and not offer misidentifications to naturally occurring and anomalous odors in the environment. Developing training aids to achieve odor chemical profile generalization capabilities in VR canines requires a more exact understanding of the VOC profiles associated with the decomposition of human remains and a better of understanding of the learning capabilities of the canines. 


\section{Operational Implications}

In a recent Supreme Court of the United States ruling, the court stated that a defendant must have an opportunity to challenge evidence of a dog's reliability, whether by crossexamining the testifying officer or by introducing his own fact or expert witnesses. The defendant may contest the adequacy of a certification or training program, perhaps asserting that its standards are too lax or its methods faulty [42]. As stated earlier, prior to the use of mimics to train VR canines for use in criminal investigations, it is important to adequately screen the synthetic mimics to determine the possible presence of the mimic compound(s) at their specified ratios in the environment, health hazards posed by the mimics, ability of a canine to be trained to positively respond to the mimic, and ability of the mimic-trained canine to find the actual target odor without responding to non-target substances normally encountered in operational searches [39]. In the absence of any peer-reviewed determination of compounds being used by canines to identify human decomposition odor and further required training and testing of dogs using only the synthetic mimic, the Sigma-Aldrich products studied herein for the odor association training and certification of VR canines applied in law enforcement investigations failed to demonstrate their effectiveness; however, there have been recommendations [17] and some anecdotal successes when actual remains are used in conjunction with these formulations.

In an operational setting where a VR canine trained and certified using synthetic training aids finds a decomposing body, the discovery reinforces the belief that the mimic works and the dog is actually proficient in identifying the odor of human decomposition. In reality, the canine may only be responding to the strong smelling anomaly (dead body) present in the environment. If the same canine positively responds to a car believed to have been used to transport or store a dead body, absent recoverable evidence, it is unclear what level of confidence the courts should give to that positive response when the dog has been trained on a product where the presence of the mimic compound(s) in the environment and the ability of the mimic-trained canine to find the actual target odor without responding to non-target substances normally encountered in operational searches had not been assessed. Human remains detection canine handlers that find themselves involved in a criminal case may have to provide evidence (testimony) at court proceedings. Training records and methodology are likely to be examined and the inclusion of mimics brought into question. The inclusion of canine training mimics that have not been 
sufficiently tested and do not accurately represent the odor of human decomposition introduces a potential risk of having an adverse affect upon the reliability and integrity of the detection team. As a consequence the canine evidence may not be admitted.

Another consequence in the use of mimics can be demonstrated in scientific papers peerreviewed without sufficient canine subject matter expertise. In Effects of training paradigms on search dog performance, Lit, et al., compares the performance of law enforcement certified dogs trained as single purpose (live find) against dual-purpose (live find and cadaver) [43]. While Lit, et al., used a hidden person to test the capabilities of the dogs to find a live person, PseudoCorpse $^{\mathrm{TM}}$ was used to test the cadaver dogs. In apparent good faith, Lit, et al., used an insufficiently tested product to determine and report canine performance [43]. Unfortunately, reports such as these are frequently used by the courts to determine canine team proficiency and ultimately evidence admission.

\section{References}

[1] Syrotuck WG. Scent and the Scenting Dog: Barkleigh Productions, Inc; 1972.

[2] Kaldenbach J. K9 Scent Detection. Calgary, Alberta, Canada: Detselig Enterprises Ltd; 1998.

[3] Schoon A, Haak R. K9 Suspect Discrimination: Training and Practicing Scent Identification Line-ups. Calgary, Alberta, Canada: Detselig Enterprises LTD; 2002.

[4] Killam EW. The Detection of Human Remains. 2nd ed. Springfield, Illinois: Charles C Thomas Publisher; 2004.

[5] Stejskal SM. Death, Decomposition, and Detector Dogs: From Science to Scene. Boca Raton, FL: CRC Press; 2012.

[6] Mesloh C, Henych M, Wolf R. Sniff test: Utilization of the law enforcement canine in the seizure of paper currency. Journal of Forensic Identification. 2002;52:704.

[7] Furton KG, Hong Y-C, Hsu Y-L, Luo T, Rose S, Walton J. Identification of odor signature chemicals in cocaine using solid-phase microextraction-gas chromatography and detector-dog response to isolated compounds spiked on U.S. paper currency. Journal of Chromatographic Science. 2002;40:147-55. 
[8] Harper RJ, Almirall JR, Furton KG. Identification of dominant odor chemicals emanating from explosives for use in developing optimal training aid combinations and mimics for canine detection. Talanta. 2005;67:313-27.

[9] Furton KG, Myers LJ. The scientific foundation and efficacy of the use of canines as chemical detectors for explosives. Talanta. 2001;54:487-500.

[10] Ozcan SS, Akin H, Bayram H, Bas M, Yildiz A, Ozdemiroglu A. Utilization of police dogs: a Turkish perspective. Policing: An International Journal of Police Strategies \& Management. 2009;32:226-37.

[11] Stockham RA, Slavin DL, Kift W. Specialized use of human scent in criminal investigations. Forensic Science Communications. 2004;6.

[12] Denver M, Perez J, Aguirre BE. Local search and rescue teams in the United States. Disaster Prevention and Management. 2007;16:503 - 12.

[13] Tomaszewski T, Girdwoyn P. Scent identification evidence in jurisdiction (drawing on the example of judicial practice in Poland). Forensic Science International. 2006;162:191-5.

[14] Lasseter AE, Jacobi KP, Farley R, Hensel L. Cadaver dog and handler team capabilities in the recovery of buried human remains in the Southeastern United States. Journal of Forensic Sciences. 2003;48:617-21.

[15] Fenton V. The use of dogs in search, rescue and recovery. Journal of Wilderness Medicine. 1992;3:292-300.

[16] Komar D. The use of cadaver dogs in locating scattered, scavenged human remains: preliminary field test results. Journal of Forensic Sciences. 1999;44:405-8.

[17] Rebmann A, David E, Sorg MH. Cadaver Dog Handbook: Forensic Training and Tactics for the Recovery of Human Remains: CRC Press LLC; 2000.

[18] Dupras TL, Schultz JJ, Wheeler SM, Williams LJ. Forensic Recovery of Human Remains: Archaeological Approaches. Boca Raton, FL: CRC Press; 2006.

[19] Battaglia TS. D'Andre Lane found guilty of murder in death of daughter Bianca Jones. Detroit Free Press2012.

[20] Hoffman EM, Curran AM, Dulgerian N, Stockham RA, Eckenrode BA. Characterization of the volatile organic compounds present in the headspace of decomposing human remains. Forensic Science International. 2009;186:6-13.

[21] Furton KG. Improving Canine Consistency By Employing Field Calibrants and International Best Practices. Penn Vet International Working Dog Conference2011. 
[22] Statheropoulos M, Agapiou A, Spiliopoulou C, Pallis GC, Sianos E. Environmental aspects of VOCs evolved in the early stages of human decomposition. Science of The Total Environment. 2007;385:221-7.

[23] Statheropoulos M, Spiliopoulou C, Agapiou A. A study of volatile compounds evolved from the decaying human body. Forensic Science International. 2005;153:147-55.

[24] Vass AA, Smith RR, Thompson CV, Burnett MN, Wolf DA, Synstelien JA, et al. Decompositional odor analysis database. Journal of Forensic Sciences. 2004;49:760-9.

[25] Vass AA, Smith RR, Thompson CV, Burnett MN, Dulgerian N, Eckenrode BA. Odor analysis of decomposing buried human remains. Journal of Forensic Sciences. 2008;53:384-91.

[26] Vass AA, Bass WM, Wolt JD, Foss JE, Ammons JT. Time since death determinations of human cadavers using soil solution. Journal of Forensic Sciences. 1992;37:1236-53.

[27] Jaggers KA, Rogers TL. The effects of soil environment on postmortem interval: a macroscopic analysis. Journal of Forensic Sciences. 2009;54:1217-22.

[28] Vass AA. Odor Mortis. Forensic Science International. 2012;222:234-41.

[29] Johnston JM. Canine detection capabilities: Operational implications of recent R\&D findings: Auburn University; 1999.

[30] Caldwell PT, Tipple CA, Stockham RA, Dulgerian N, Eckenrode BA. Characterization of Pseudo Corpse Scents Used as Canine Training Aids. 61st Annual Conference of the Southeastern Regional Meeting of the American Chemical Society. San Juan, Puerto Rico2009.

[31] Tipple CA, Beussman D, Caldwell PT, Kile B, Stockham RA, Dulgerian N, et al. Characterization and Testing of Canine training Aids for Forensic Victim Recovery Investigations. 63rd Annual Conference of the American Academy of Forensic Sciences. Chicago, IL2011.

[32] Sloan KM, Mustacich RV, Eckenrode BA. Development and Evaluation of a Low Thermal Mass Gas Chromatograph for Rapid Forensic GC-MS Analyses. Field Analytical Chemistry and Technology. 2001;5:288-301.

[33] Scientific Working Group on Dog and Orthogonal detector Guidelines (SWGDOG; http://swgdog.fiu.edu/approved-guidelines/).

[34] Snyder DL, Caldwell PT, Dulgerian N, Eckenrode BA. Human and Animal Decomposition Analysis in Contained Biotope Conditions. OnSite 2012, 20th International Conference of OnSite Analysis for Homeland Security, Forensics, and Environmental Remediation. Baltimore, MD2012. 
[35] The Merck Index: An Encyclopedia of Chemicals, Drugs, and Biologicals. 12th ed. Whitehouse Station, NJ: Merck and Co., Inc.; 1996.

[36] Dent BB, Forbes SL, Stuart BH. Review of human decomposition processes in soil. Environmental Geology. 2004;45:576-85.

[37] Lundgren DW, Hankins J. Metabolism of Putrescine to 2-Pyrrolidone by Rat Liver Slices. The Journal of Biological Chemistry. 1978;253:7130-3.

[38] Lundgren DW, Fales HM. Metabolism of Putrescine to 5-Hydroxy-2-pyrrolidone via 2Pyrrolidone. The Journal of Biological Chemistry. 1980;255:4481-6.

[39] Stadler S, Stefanuto P-H, Byer JD, Brokl M, Forbes S, Focant J-F. Analysis of synthetic canine training aids by comprehensive two-dimensional gas chromatography-time of flight mass spectrometry. Journal of Chromatography A. 2012;1255:202-6.

[40] Settles GS, Kester DA. Aerodynamic sampling for landmine trace detection. SPIE Aerosense. 2001;4394:108.

[41] Filipiak W, Sponring A, Mikoviny T, Ager C, Schubert J, Miekisch W, et al. Release of volatile organic compounds (VOCs) from the lung cancer cell line CALU-1 in vitro. Cancer Cell International. 2008;8.

[42] Florida v. Harris, Supreme Court of the United Sates, No. 11-817. 2013.

[43] Lit L, A.Craword C. Effects of training paradigms on search dog performance. Applied Animal Behavior Science. 2006;98:277-92. 


\section{Figure Captions}

Figure 1. Flow diagram of the various analysis methods used in this study for each of the formulations characterized. On the left is the process for PSI and PSII, while the right side side is the process for PSDV.

Figure 2. Schematic of the outdoor (a) and indoor (b) canine trials performed. The outdoor image shows six target locations: 1) PSII, 2) isopropanol, 3) PSDV, 4) water, 5) PSI, 6) positive control. The indoor image shows five odor stations, with two pad testing containers at each station. The layout of the indoor tests performed in the buckets was performed in a room very similar to the one depicted above.

Figure 3. The layout of the odor stations (1-5) and buckets (6-8) used in the indoor odor discrimination tests. Blanks (B), negative controls (NC), distractors (D), and positive controls (PC) were all randomly placed within each testing matrix.

Figure 4. Total ion current chromatograms of the liquid injections for the three formulations characterized. The top panel is PSI, with (1) 2-pyrrolidinone and (2) 4-aminobutanoic acid. The middle panel is PSII, with (1) putrescine (2) cadaverine (3) 2-pyrrolidinone and (4) 4aminobutanoic acid. The bottom panel is PSDV, with (1) 2-pyrrolidinone and (2) 4aminobutanoic acid.

Figure 5. Surface plot showing the two-dimensional chromatographic results of the liquid analysis of Pseudo ${ }^{\mathrm{TM}}$ Scent II using the Pegasus 4D system.

Figure 6. Total ion current chromatograms for the 16 hour static SPME sampling of the three formulations characterized. Background subtraction was applied to reduce siloxane peaks.

Figure 7. Chromatograms for the ACEM sampling of the three formulations characterized (blue traces) when compared to the background (red traces). The top panel is PSI, the middle panel is PSII, and the bottom panel is PSDV.

Table 1. List of compounds observed in the SPME analysis of the three Pseudo Scent formulations. A compound was only reported as being observed in the table if it was identified in all three runs. 


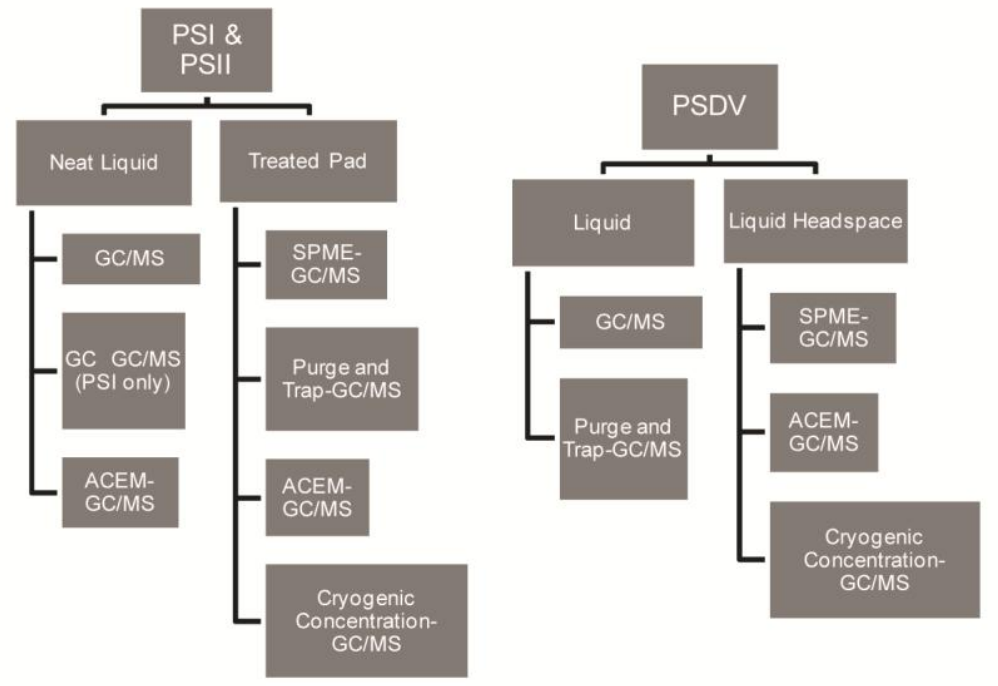




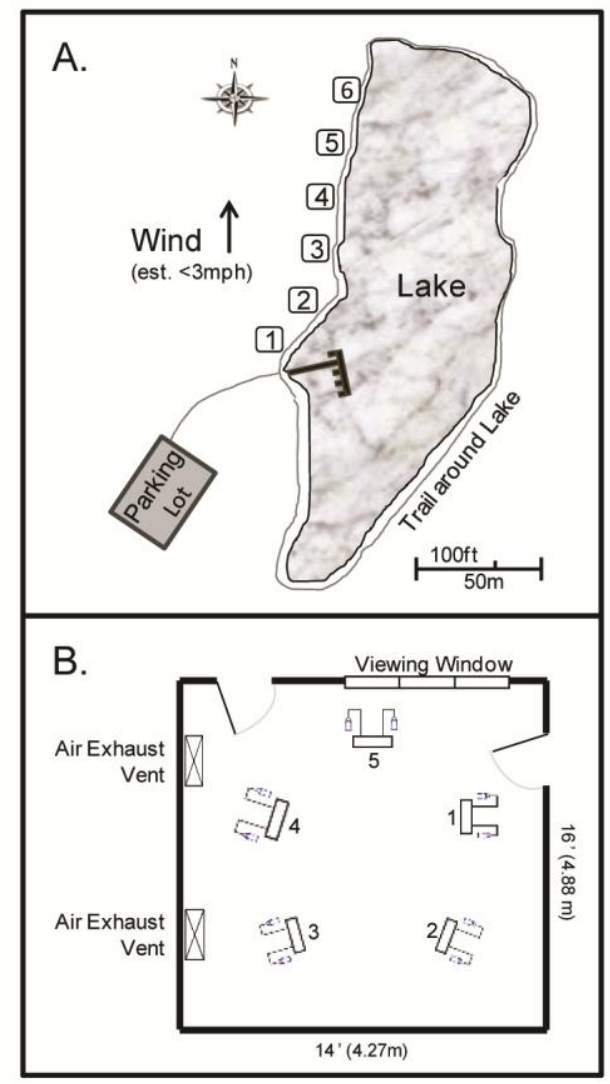




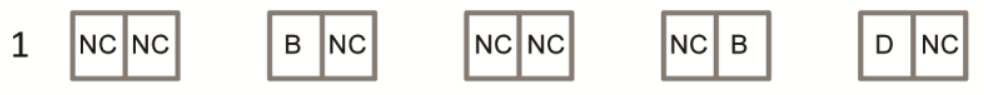

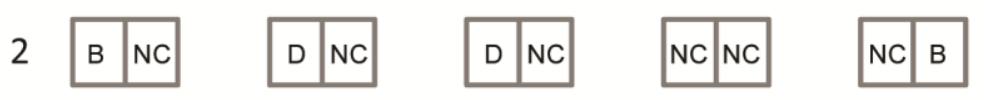
\begin{tabular}{|l|l|l|l|l|l|l|l|l|}
\hline $\mathrm{NC}$ & $\mathrm{NC}$ \\
\hline
\end{tabular}$\quad$\begin{tabular}{ll|l|l|}
$\mathrm{B}$ & $\mathrm{D}$ \\
$\mathrm{NC}$ & $\mathrm{NC}$ & $\mathrm{NC}$ & $\mathrm{NC}$ \\
\hline
\end{tabular}
\begin{tabular}{|l|l|l|l|l|l|l|l|l|l|l|}
\hline $\mathrm{D}$ & $\mathrm{NC}$ \\
\hline $\mathrm{NC}$ & $\mathrm{NC}$ & $\mathrm{B}$ & $\mathrm{B}$ \\
\hline
\end{tabular}$\quad$\begin{tabular}{|l|l|}
$\mathrm{NC}$ & $\mathrm{NC}$ \\
\hline
\end{tabular}

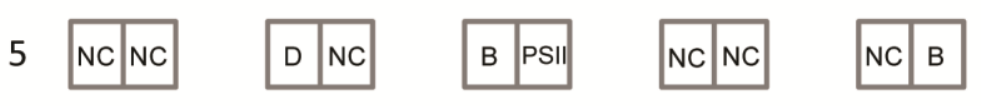

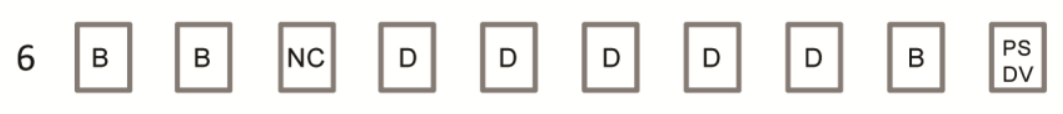

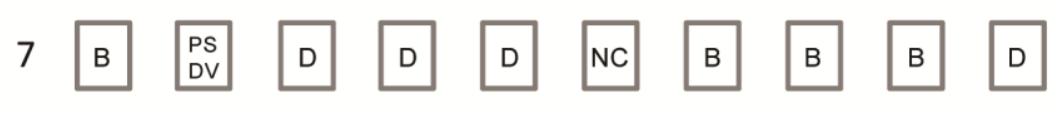

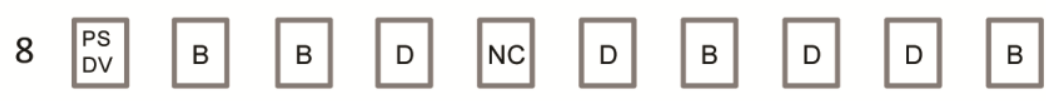



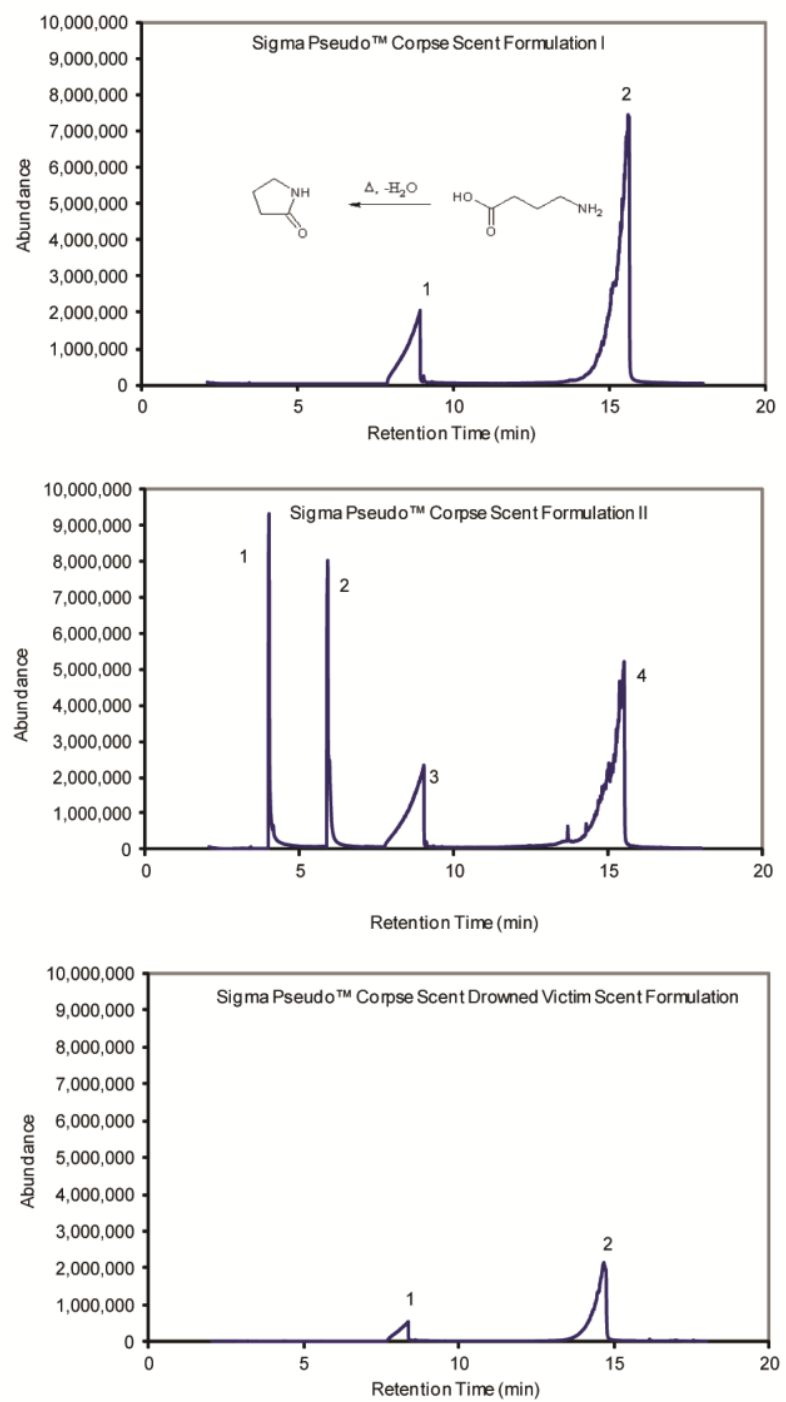


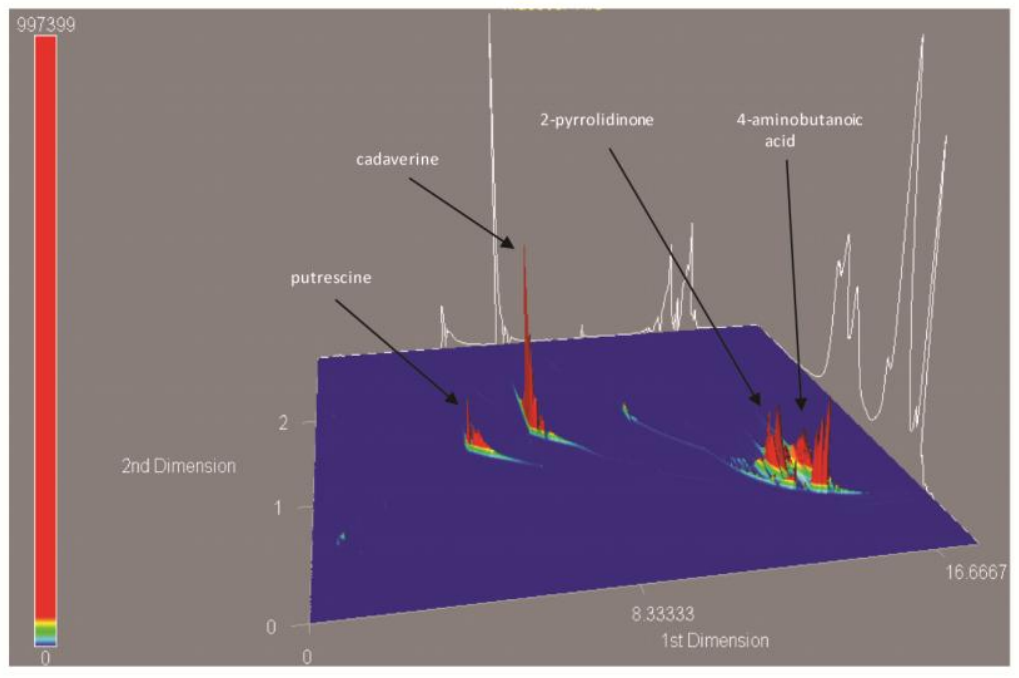



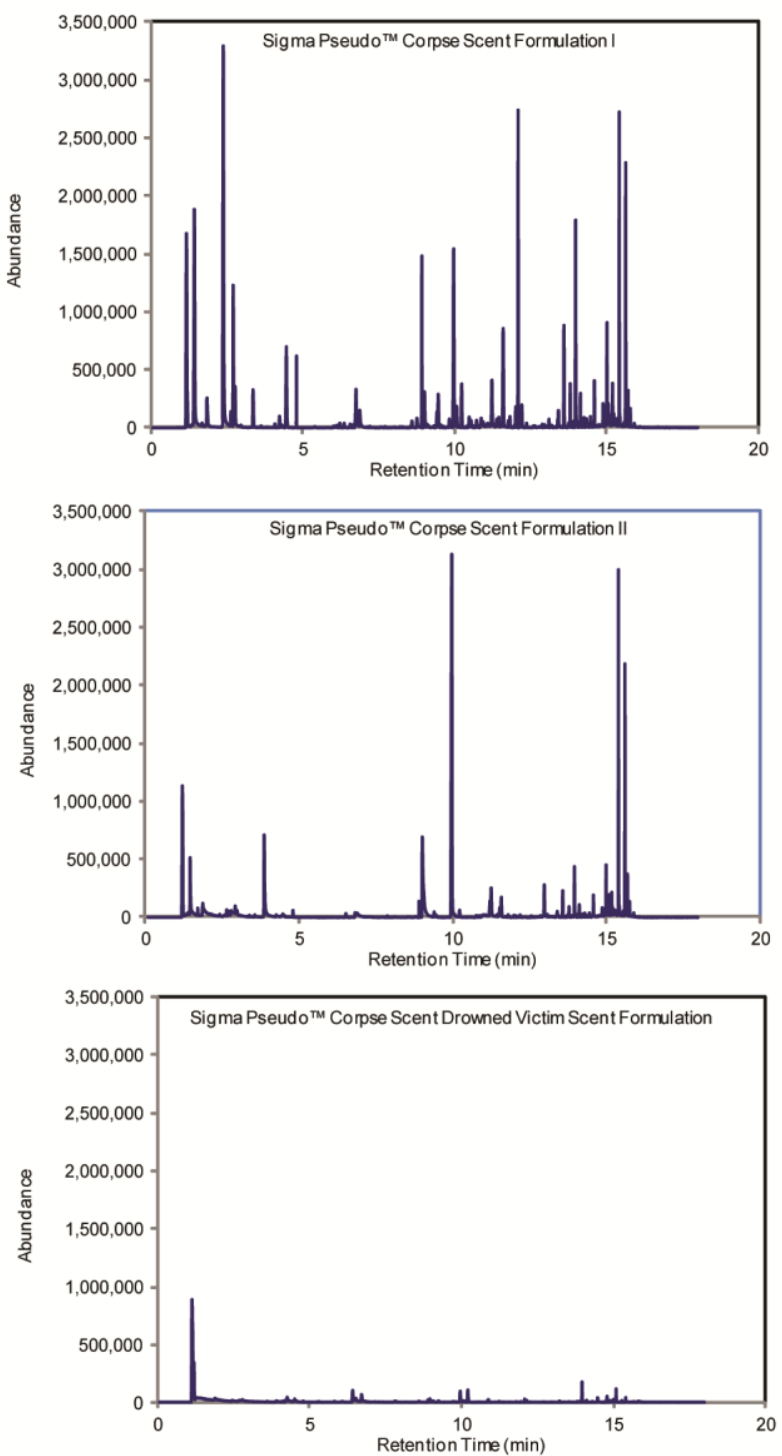

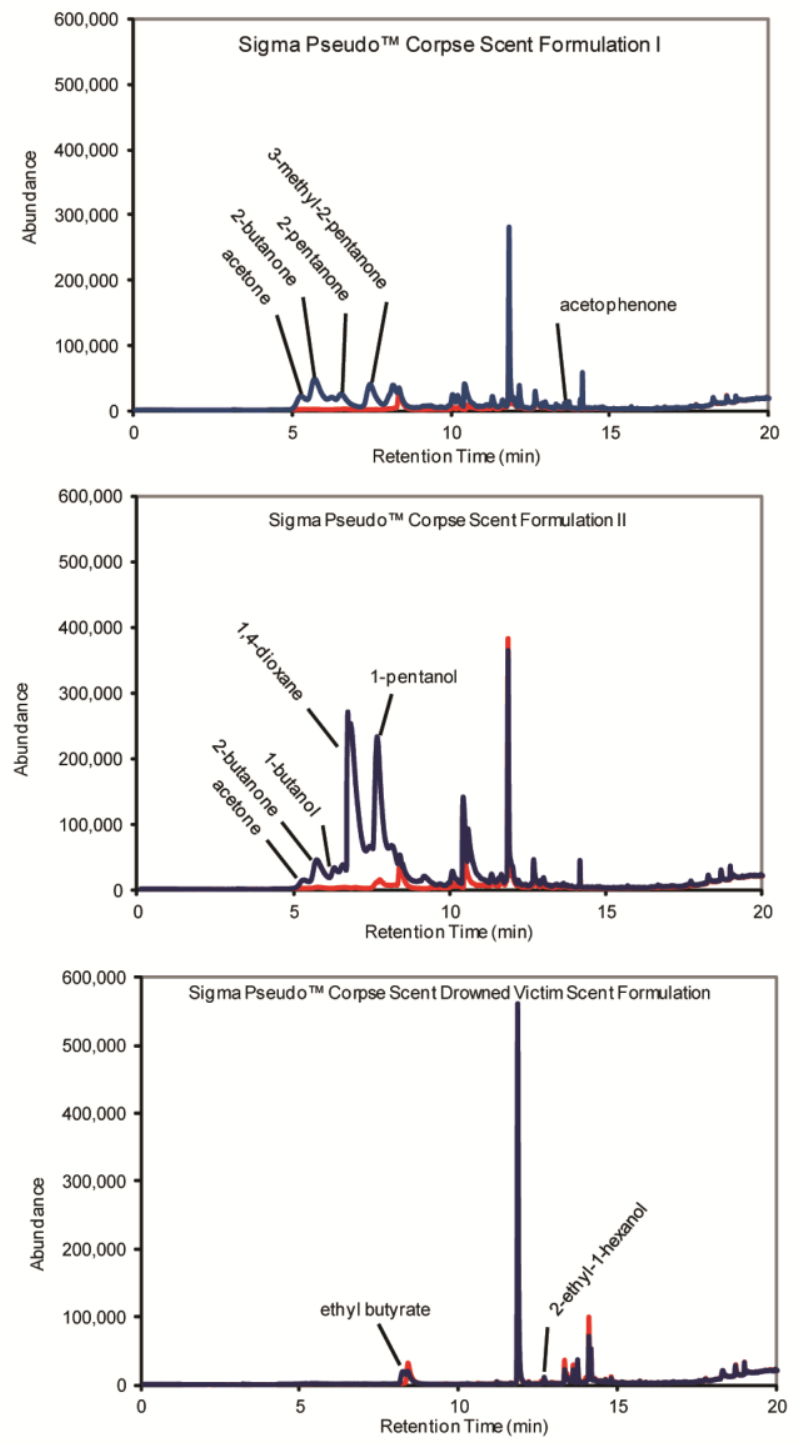


\begin{tabular}{|c|c|c|c|}
\hline \multirow[t]{2}{*}{ Compound Observed } & Pseudol & Pseudo II & Drowned \\
\hline & $16 \mathrm{hr}$ & $16 \mathrm{hr}$ & $16 \mathrm{hr}$ \\
\hline acetone & $x$ & $x$ & \\
\hline 2-butanone & $x$ & & $x$ \\
\hline \multicolumn{4}{|l|}{ 2-pentanone } \\
\hline 1-butanol & $x$ & & \\
\hline 3-methyl-2-pentanone & & & $x$ \\
\hline 1,4-dioxane & & $x$ & \\
\hline heptane & $x$ & & \\
\hline 2,4-dimethyl-furan & $x$ & $x$ & \\
\hline 1-pentanol & & $x$ & $x$ \\
\hline methyl isobutyl ketone & $x$ & & \\
\hline octane & $x$ & & \\
\hline hexanal & $x$ & & \\
\hline methoxy-phenyl-oxime & $x$ & & \\
\hline heptanal & $x$ & & \\
\hline 3-hexanol & & & $x$ \\
\hline \multicolumn{4}{|l|}{ 2-hexanol } \\
\hline 3-heptanol & & & $x$ \\
\hline 3-ethyl-2-pentanone & & & $x$ \\
\hline 2-butoxy-ethanol & $x$ & & \\
\hline 3-hexanone & & & $x$ \\
\hline 3-heptanone & & & $x$ \\
\hline 2-heptanone & & $x$ & $x$ \\
\hline phenol & $\mathrm{x}$ & $\mathrm{x}$ & \\
\hline 2,4,6-trimethyl-pyridine & $x$ & $x$ & \\
\hline 3-octanol & & & $x$ \\
\hline octanal & & $x$ & \\
\hline 3-ethyl-3-heptanol & & & $x$ \\
\hline 2-ethyl-1-hexanol & & $\mathrm{x}$ & $x$ \\
\hline 3-methyl-3-heptanol & & & $x$ \\
\hline 4-ethyl-1,3-benzenediol & & $x$ & \\
\hline 2-nonanone & & $x$ & \\
\hline 2-decanone & & $x$ & \\
\hline benzothiazole & $x$ & $x$ & \\
\hline 1,3-bis(1,1-dimethylethyl)-Benzene & $x$ & & \\
\hline \multicolumn{4}{|l|}{ 1,3-ditertiarybutyl Benzene } \\
\hline tetradecane & $x$ & & \\
\hline $\begin{array}{l}\text { 2-methyl-,1-(1,1-dimethylethyl)-2-methyl-1,3- } \\
\text { propanediyl propanoic acid }\end{array}$ & $x$ & $x$ & \\
\hline benzophenone & $x$ & $\mathrm{x}$ & \\
\hline 2,4-bis(1,1-dimethylethyl)-phenol & & $x$ & $x$ \\
\hline 3-ethyl-3-octanol & & & $x$ \\
\hline nonanal & & & \\
\hline
\end{tabular}




\section{Acknowledgements}

The authors would like to thank Darrin Turpin, Dan Downs, Craig Schultz and Jan Topoleski as members of the Forensic Canine Program within the Evidence Response Team Unit of the FBI Laboratory for their insights on the use of canine training aids. The authors would also like to thank Gene Peters of the Counterterrorism and Forensic Science Research Unit and Jason Bannan for their valuable contributions. This research was supported in part by an appointment to the Research Participation Program at the Federal Bureau of Investigation, Counterterrorism and Forensic Science Research Unit, which is administered by the Oak Ridge Institute for Science and Education through an interagency agreement between the U.S. Department of Energy and the FBI. It was under this program that Dr. Whitchurch performed this work.

\section{Disclaimer}

This publication is number 13-18 of the Laboratory Division of the Federal Bureau of Investigation (FBI). Names of commercial manufacturers are provided for identification purposes only, and inclusion does not imply endorsement by the FBI. The views expressed in this article are those of the authors and do not necessarily reflect the official policy or position of the FBI or U.S. Government. One or more of the authors is a U.S. Government employee and prepared this work as part of that person's official duties. Title 17 United States Code (U.S.C.) Section 105 provides that "Copyright protection under this title is not available for any work of the United States Government." Title 17 U.S.C. Section 101 defines a United States Government work as a "work prepared by an employee of the United States Government as part of that person's official duties." 